\title{
Las múltiples implicancias espaciales de la difusión del COVID-19. Un estado de la cuestión
}

Perla Zusman

CONICET - Universidad de Buenos Aires. Facultad de Filosofía y Letras. Instituto de Geografía "Romualdo Ardissone". Buenos Aires, Argentina.

\section{Gonzalo Lus Bietti}

Universidad de Buenos Aires. Facultad de Filosofía y Letras. Instituto de Geografía "Romualdo Ardissone". Buenos Aires, Argentina.

\section{Gabriela Landini \\ Universidad de Buenos Aires. Facultad de Filosofía y Letras. Instituto de Geografía "Romualdo Ardissone". Buenos Aires, Argentina.}

\begin{abstract}
Resumen
Este artículo tiene por objetivo identificar las preocupaciones conceptuales y temáticas que se observan en los textos publicados sobre el COVID-19 en el campo de la Geografía, al poco tiempo de expansión de la dolencia a nivel mundial. A la vez que se persigue desnaturalizar y politizar la pandemia, se observa un interés por demostrar que el espacio es una dimensión significativa en la interpretación de su difusión y en el modelaje de las implicancias sociales. Las cuestiones recurrentemente discutidas en los textos son la relación de la pandemia con el régimen de acumulación neoliberal y la globalización, el Estado y el control de la movilidad sobre los cuerpos, las vulnerabilidades económicas, sanitarias y educativas, los cuidados y el hogar, y los desafíos que la pandemia plantea para el futuro tanto para el planeta como para la geografía en cuanto disciplina.
\end{abstract}

PALABRAS CLAVE: COVID-19. ESPACIO. GEOGRAFÍA. FUTURO

The multiple spatial implication of the spread of COVID-19. A state of art

\begin{abstract}
The aim of this paper is to identify conceptual and thematic concerns that appear on articles on COVID-19 published in the field of Geography, shortly after the disease was spread worldwide. On one hand, they seek to denaturalize and politicize the pandemic. On the other, they show that space is a significant dimension that plays an important role in order to understand COVID-19 diffusion as well as to make models of its social implications. Recurring issues discussed on these papers are the relationship between
\end{abstract}


pandemic, neoliberal accumulation regime and globalization, the state and control of mobility over bodies, economic, health and educational vulnerabilities, care and home, future challenges that the pandemic poses for the earth and for geography as a discipline.

KEY WORDS: COVID-19. SPACE. GEOGRAPHY. FUTURE

\section{Introducción}

La enfermedad causada por el Síndrome Respiratorio Agudo Severo Coronavirus 2 (COVID-19) declarada como pandemia por la Organización Mundial de la Salud en el mes de febrero de 2020 llevó, hacia mediados de marzo del mismo año, a la mayor parte de los académicos y académicas en ciencias sociales de Europa y América a quedarse en sus casas, a dar clases a sus alumnos y alumnas universitarios través de diferentes plataformas digitales y a participar de debates sobre las causas e impactos en los modos de vida desde distintas perspectivas y a distintas escalas.

Estas actividades fueron acompañadas por la elaboración de reflexiones volcadas rápidamente en publicaciones de las distintas disciplinas, casi simultáneamente a aquellas que desde la medicina o biología ofrecían resultados sobre investigaciones en términos de pruebas de identificación del virus, tratamientos y avances en el desarrollo de vacunas. En este contexto, los campos de conocimiento de las humanidades recuperaron su bagaje teórico y metodológico a los fines de interpretar la coyuntura y a formular escenarios post-pandemia para el corto y mediano plazo.

Las contribuciones en el campo de la Geografía recuperan aquella idea de Doreen Massey (2012) el "espacio importa" en la medida que aquellos atributos concebidos clásicamente como inherentes al mismo están presentes en las dinámicas que facilitan la expansión del virus (distancia, densidad, escala, circulación). A su vez, dichas aportaciones persiguen desnaturalizar y politizar la pandemia. En el momento de comenzar este estado del arte, a menos de seis meses de iniciada la pandemia, quedamos sorprendidos por la cantidad de publicaciones disciplinarias que abordaron las implicancias espaciales de la expansión del COVID-19.

Frente a la abundancia de contribuciones, hemos decidido tomar en cuenta aquellas publicaciones que manifestaran mayor pluralidad de perspectivas y voces representativas de experiencias vivenciadas en distintas partes del mundo. Del mundo iberoamericano hemos tomado en cuenta las aportaciones editadas en la Sección Reflexiones sobre la crisis COVID-19 (Asociación Española de Geografía), la publicación Geopolítica(s) Revista de estudios sobre espacio y poder No11 (Universidad Complutense de Madrid), los números 17 y 18 de Economía e Espaço (Nucleo de Estudos em Espaço e Economia, Universidad del Estado de Rio de Janeiro), Tamoios No16 (Facultad de Formación de Profesores, Universidad del Estado de Rio de Janeiro, San Gonzalo), el número especial de Hygeia-Revista Brasileira de Geografia Médica e da Saúde, y los textos incluidos en Posición No3 (Instituto de Geografía, Universidad de Luján). Del mundo anglosajón se han incorporado las contribuciones de las siguientes publicaciones: Dialogues in Human Geography No10 (2) (SAGE), Journal of Latin American Geography No19 (3) (CLAG, Universidad de Texas) y Tourism Geographies $\mathrm{N}^{\circ} 22$ (3) (Taylor \& Francis). A 
ellos hemos sumado la lectura de ciertos referentes en los debates como David Harvey (2020), Mathew Sparke y Dimitar Anguelov (2020) y Joseph Oppong (2020).

Las preguntas que orientaron nuestra aproximación a estos textos fueron las siguientes: ¿̇en el marco de qué discusiones se establece el vínculo con el COVID-19?, ¿qué problemas espaciales previos se reconocen?, ¿qué conceptos se incorporan en la discusión?, ¿qué desafíos se plantean para el futuro?, ¿qué desafíos plantea el COVID-19 para la Geografía en tanto disciplina y práctica profesional?

El artículo se encuentra dividido en siete secciones que dan cuenta de las temáticas que aparecen de forma recurrente en la bibliografía seleccionada. Ellas son: el régimen de acumulación neoliberal y la globalización; las escalas, el Estado y el control de la movilidad sobre los cuerpos; vulnerabilidades sanitarias, económicas y educativas; los cuidados y sus ambivalencias; la espacialidad de la "nueva" normalidad: perspectivas a futuro; los aportes de la geografía, y las geografías académicas futuras.

\section{El régimen de acumulación neoliberal y la globalización}

El origen y expansión del virus COVID-19 es entendida como expresión de las relaciones capitalistas neoliberales que moldearon la forma de globalización que atraviesa el mundo actual.

Así, gran parte de las reflexiones elaboradas en el contexto brasileño acuden a la idea de globalización perversa acuñada por Milton Santos (2004) para caracterizar el estado de situación previo a la pandemia, en el marco del cual se habría degradado a la naturaleza, marginado amplios sectores de la población, segregado territorios y privatizado servicios básicos, como el de la salud (Barbosa, 2020; Bernardes et al., 2020; Cardoso Rodrigues y Cardoso Rodrigues, 2020; Cataia, 2020; Fortes, et al., 2020; Machado et al., 2020; Magalhães et al., 2020; Neto y Castro, 2020; Nossa, 2020; Pereira et al., 2020; Porto-Gonçalves, 2020a, 2020b; Ramos, 2020; Rocha, 2020; Roxo, 2020; Silva, 2020; Zanotelli y Dota, 2020).

Más precisamente, estas aproximaciones destacan la escasa sustentabilidad del régimen de acumulación capitalista neoliberal, basada en una visión de la naturaleza separada y exterior a la cultura, la economía y la vida diaria (Harvey, 2020). Así, la pérdida de biodiversidad, la fragmentación de los ecosistemas (Gómez Mendoza, 2020; Gutiérrez Hernández, 2020; Nel-lo, 2020; Vegas Gallo, 2020), e incluso el monocultivo y la explotación animal que forman parte del sistema alimentario (Alentejano, 2020), hablan del carácter extractivo de las prácticas que habrían llevado tanto a la aparición de especies patógenas como a la aproximación de especies exóticas a los hábitats de las sociedades humanas. Este tipo de prácticas fueron denunciadas desde hace décadas tanto por movimientos ambientalistas como por las comunidades indígenas (Bringel, 2020).

Neto y Castro (2020) recuperan la visión de Neil Smith sobre la relación entre capitalismo y naturaleza para comprender que la pandemia se presenta como un desastre social intrínsecamente asociado con la lógica de circulación del capitalismo globalizado. Pero es el propio David Harvey que, en un texto publicado al poco tiempo de la difusión del COVID-19 en Occidente, ofrece más detalles sobre esta relación: "Si yo quisiese 
ponerme antropomórfico y metafórico en esto, yo concluiría que el COVID-19 constituye una venganza de la naturaleza por más de cuarenta años de grosero y abusivo maltrato a manos de un violento y desregulado extractivismo neoliberal" (Harvey, 2020:18). Desde su punto de vista, se pone en evidencia, por un lado, el modelo de la economía capitalista con una dinámica en espiral de infinita expansión y crecimiento y, por el otro, el entrecruzamiento entre las contradicciones internas de la circulación y acumulación del capital, y la reproducción social en una relación metabólica con la naturaleza.

Si bien los textos señalan que la difusión de dolencias anteriores como el SARS o el EBOLA fueron anticipatorias de esta pandemia, la propagación del COVID-19 tuvo en un corto tiempo un alcance global. Ello se asociará a las condiciones de fluidez e interdependencia que se habrían acentuado en las dos últimas décadas a partir del aumento de la conectividad, del crecimiento de las redes de comunicación global y, en particular, de aquellas de transporte aéreo.

Siguiendo esta línea, algunos trabajos señalan que el virus da cuenta de las dinámicas de glocalización (Méndez, 2020; Murray y Cañada, 2020; Pillet Capdepón, 2020) en las que fenómenos, en principio ajenos y lejanos, acaban incidiendo de forma intensa sobre el entorno próximo. De hecho, una vez que el virus llega al territorio de un determinado país se esparce en un sentido metropolitano y comunitario y, desde allí, a otras ciudades de la red urbana (Azeredo Rodrigues, 2020; Barbosa, 2020; Castilho, 2020; Gomes de Aguiar et al., 2020; Goveia, 2020; Lima et al., 2020; Martinuci et al., 2020a; Monié, 2020; Pereira Caldas et al., 2020; Ribeiro, 2020; Santana Juárez et al., 2020; Sodoré et al., 2020; Silva y Muniz, 2020; Souza y Ferreira Junior, 2020; Vicente Ferreira et al., 2020). De esta manera, el desplazamiento del virus se daría a través de un movimiento que iría desde territorios-red hacia territorios-zona (Haesbaert, 2020).

\section{Las escalas. El Estado y el control sobre la movilidad de los cuerpos}

Algunos textos señalan que la circulación global del virus se encuentra mediada por el accionar de instituciones gubernamentales y no gubernamentales situadas a distintas escalas (Saracho López, 2020). A la vez que se analizan las asociaciones interescalares, los estudios visibilizan el hecho de que escalas que apenas eran tratadas en el marco de la geografía como la del hogar, la del cuerpo (ambas incorporadas en la disciplina por los estudios feministas) y la del genoma (Blue y Rock, 2020) adquirieron mayor protagonismo en el contexto de la pandemia.

Se afirma que los actores que participan de la construcción de las distintas escalas asumen diversos grados de responsabilidad en su gestión. De hecho, los organismos globales multilaterales (la Unión Europea, el Fondo Monetario Internacional o la Organización de Estados Americanos) parecería que apenas se implicaron en el diseño de propuestas de financiamiento de la crisis sanitaria (Castanho, 2020; Gómez Mendoza, 2020; Lozano Valencia, 2020; Marcu, 2020). Solo las Organizaciones Mundial y Panamericana de la Salud habrían adquirido mayor compromiso al proponer criterios para el diagnóstico o la prevención. Del mismo modo, la Comunidad de Estados Latinoamericanos y Caribeños (CELAC) ha propuesto escenarios de discusión epidemiológica a nivel regional (Sierra, 2020a, b). Se destaca que fueron los Estados nacionales, con 
infraestructuras sanitarias devaluadas por el neoliberalismo, los que, en la mayor parte de los países, salieron a la escena a gestionar la pandemia. Ellos dictaron las medidas de confinamiento que establecieron el cierre de las fronteras de los territorios bajo su dominio y limitaron la circulación de personas y mercaderías (Pastor, 2020). A la vez, buscaron equiparse sanitariamente a través de la compra en el exterior o la producción local de insumos médicos (barbijos, reactivos químicos, hisopos, ventiladores) y también ofrecieron apoyos financieros a los sectores más afectados por la parálisis de las economías.

Algunos artículos se aproximan a las posiciones de los líderes de países para quienes cualquier política que supusiera el aislamiento de la población en sus casas desembocaría en una crisis económica. Los casos paradigmáticos abordados fueron los de Estados Unidos (Agnew, 2020) y Brasil (Conde, 2020; Pfrimer y Barbosa, 2020) cuyos presidentes hicieron caso omiso a la crisis sanitaria. En estas situaciones fueron las autoridades situadas a otras escalas (gobernadores, autoridades municipales) las que tuvieron que hacerse cargo de administrar la pandemia. En el caso de Brasil se hace referencia a las acciones del Consorcio Interestatal de Desarrollo Sostenible del Nordeste, que presentó una actitud opuesta a la del presidente, reconociendo la gravedad de la situación sanitaria y aconsejando seguir las medidas preventivas recomendadas por la Organización Mundial de la Salud (Rossi y Silva, 2020). Actitudes preventivas también fueron llevadas adelante en las favelas promovidas por las organizaciones locales de toda índole, desde las asociaciones de vecinos hasta las de narcotraficantes (Conde, 2020).

La literatura destaca que, en general, los Estados mostraron más actitudes de competencia entre sí que de colaboración. Sin embargo, se identifican conductas solidarias por parte de China al ofrecer cooperación a nivel internacional en términos de material sanitario y de personal epidemiológico. Estas ayudas, junto a la eficiencia en el control de la pandemia, son leídas por los estudios geopolíticos como un soft power que le otorga a China un nivel de liderazgo respecto de Estados Unidos (Gómez Mendoza, 2020; Loyer y Giblin, 2020, Manero, 2020; Méndez, 2020). Otro país que ha llevado adelante una política colaborativa es Cuba, dando apoyo a través de sus médicos (con experiencia en el control del Ébola) a China, Italia, España y Andorra (Huish, 2020).

Las formas de administración de la pandemia fueron interpretadas como expresión y visibilización de los modos en que los poderes ejercen un control institucional sobre los cuerpos. Estas prácticas, conceptualizadas por Foucault bajo el término de biopolítica, se expresarían en el contexto de difusión del COVID-19 de tres formas. En primer lugar, en las distintas acciones orientadas a evitar la diseminación de los contagios, desde el confinamiento en los hogares (Vallejo, 2020) y la recurrencia a las fuerzas militares para asegurar el cumplimiento del aislamiento, hasta la difusión el uso de aplicativos para localizar a los enfermos y sus contactos estrechos. Mientras que la violencia provocada por la presencia de fuerzas militares en espacios públicos en áreas urbanas y también en ámbitos rurales es un tema destacado por algunos textos que encuentran su lugar de enunciación en América Latina (Benites y Bebbington, 2020; Borja y Buitrón Cañadas, 2020), la preocupación por el uso de las aplicaciones como forma de vigilancia y restricción de las libertades civiles es discutida por autores de origen europeo o asiático ${ }^{1}$ (Liu y Bennett, 2020; Chen, Marvin y While, 2020; Datta 2020).

1 El texto de Chen, Marvin y While (2020) señala que la pandemia aceleró el uso de estas tecnologías como 
En segundo lugar, algunos especialistas interpretan el uso de cartografías y gráficos orientados a visualizar la evolución de la pandemia como técnicas biopolíticas en la medida que ellas colaboran a orientar las acciones estatales o regionales. La referencia continua de científicos y políticos a la necesidad de llevar adelante acciones tendientes a "achatar la curva" en el momento en que se observan altos índices de contagios y fallecimientos en los distintos países serían un ejemplo de ello (Brice, 2020; Everts, 2020).

En tercer lugar, la noción de biopolítica es recuperada por Haesbaert (2020) para referirse las implicancias territoriales de las políticas destinadas a evitar la circulación de las personas y, con ellas, las del virus. Así, Haesbaert reconoce que las medidas de confinamiento definidas por los Estados no logran siempre constituir territorios de reclusión (un total aislamiento del resto de la sociedad), sino de contención territorial en la medida que el cierre es relativo, temporario y tiene un carácter simbólico más que material. Siempre existe la posibilidad de contornear los territorios cerrados, de descubrir otro camino para evitar los controles sanitarios como se observa entre los migrantes de Venezuela y de Ecuador a Colombia (Idler y Hochmüller, 2020).

Cabe destacar que según algunos textos no solo los Estados buscan construir territorios de reclusión en tiempos de pandemia, poblaciones indígenas tanto en los ámbitos anglosajones (como en el caso de la Isla Turtle situada en el límite entre Estados Unidos y Canadá) (Leonard, 2020) como latinoamericanos (por ejemplo, en la amazonia peruana) (Abizaid et al., 2020) cierran el ingreso a los ámbitos bajo su dominio a sociedades urbanas como medida preventiva. Sin embargo, desde el punto de vista de Leonard (2020), estos territorios no se definirían en base a su potencial de violencia, sino de curación.

\section{Vulnerabilidades sanitarias, económicas y educativas}

Algunos geógrafos y geógrafas se hicieron eco de las críticas realizadas a aquellas posturas políticas que desaconsejaron cumplir con el confinamiento y el distanciamiento social por sus consecuencias económicas. Desde el punto de vista de algunos trabajos emergentes de esa crítica, la dicotomía entre salud y economía resulta falsa, en realidad, ella expone una desvalorización de la vida. Ellos acuden al término de Achille Membe (2011) de necropolíticas ${ }^{2}$ para conceptualizar aquellas prácticas que definen quiénes merecen vivir y quiénes morir (Conde 2020, Cupples 2020; Frigotto, 2020; Fortes et al., 2020; Gómez Mendoza, 2020; Karol y Silva, 2020; Leopoldo, 2020; Machado et al., 2020; Monié, 2020; Roxo, 2020). Ramos (2020:7) sostiene que así se define políticamente: "quién tiene cómo y dónde protegerse y quién simplemente no lo tiene".

medio de control social. De otro modo, las aplicaciones hubieran sido objeto de mayor debate y hubieran penetrado más lentamente, particularmente en los ámbitos urbanos. Esta discusión es alimentada también por las reflexiones de Giorgio Agamben (2020) emitidas a los pocos días que se establecen las medidas del confinamiento en Italia. En su opinión, las medidas de emergencia suspenden las garantías constitucionales y llevan a instalar un estado de excepción. Geógrafos con conocimiento de la situación latinoamericana como Oslender (2020) critican la posición de Agamben pues consideran, en primer lugar, que la declaración de emergencia no implica la suspensión de la ley y, en segundo lugar, el confinamiento fue aconsejado por médicos y científicos como medidas de cuidado. Por su lado, Haesbaert (2020) señala que este tipo de medidas fueron comprendidas por la ciudadanía como un medio de evitar la difusión de los contagios.

2 En este marco, se destaca también la reducción a la población a números estadísticos (cantidad de muertes y contagios diarios). 
Los sectores más vulnerables en términos de edad, raza, clase y género son los más afectados por las crisis sanitarias, económicas y educacionales pues escasamente se idean estrategias orientadas a estos grupos de población. Además, estos sectores que ya se encontraban en condiciones de vulnerabilidad previamente agudizaron su situación en tiempos de pandemia (Borja y Buitrón Cañadas, 2020).

Mientras que algunos trabajos en el ámbito europeo han discutido los efectos de la pandemia entre las personas de tercera edad (Vallejo, 2020) y de los refugiados que residen en ámbitos caracterizados por su precariedad habitacional y sanitaria (Lois, 2020; Maddrell, 2020), gran parte de los artículos producidos en América Latina ha abordado la experiencia de aquellos sectores sociales que residen aglutinados en viviendas sin servicio de agua potable que garantice las condiciones de higiene necesarias para prevenir el contagio (Bernardes et al., 2020; Brouder et al., 2020; Campos y Lins, 2020; Cifuentes-Faura, 2020; Everingham y Chassagne, 2020; Higgins-Desbiolles, 2020; Méndez, 2020; Ramos, 2020; Silva, 2020). Además, se sostiene que, en muchos países de esta región, los sectores populares dependen de un sistema de salud pública amedrentado por la política de privatizaciones y por su mercantilización.

El contraste entre las áreas que cuentan con viviendas y servicios de salud para hacer frente a la difusión del COVID-19 con aquellas que no poseen estas condiciones es presentada como evidencia de la segregación socio-espacial y la fragmentación territorial entre la ciudad informal y la formal, entre los centros y las periferias: "la desinversión que se concretiza en menos hospitales, menos camas y menos equipamientos reafirma un cuadro de injusticias territoriales (Rocha, 2020:11).

En todos los casos, se destaca que la atención médica se encuentra centralizada en las grandes metrópolis, observándose la falta de una adecuada dotación de asistencia sanitaria en las ciudades medias o pequeñas y, particularmente, en las áreas rurales (Aleixo et al., 2020; Barbosa, 2020; Cataia, 2020; Cardoso Rodrigues y Cardoso Rodrigues, 2020; Farias, 2020; Fortes et al., 2020; Gonzaga et al., 2020; Lima et al., 2020; Lima e Silva, et al., 2020; Machado et al., 2020; Magalhães et al., 2020; Neto y Castro, 2020; Nossa, 2020; Ramos, 2020; Rocha, 2020; Roxo, 2020; Said y Silva, 2020; Silva et al., 2020; Silva y Muniz 2020; Simão, 2020; Zanotelli y Dota, 2020).

A la crisis sanitaria se le agrega aquella derivada de la paralización de las actividades productivas. Según la bibliografía, el desplome de los mercados financieros (en esta coyuntura, no compartido por las acciones de las tecnologías digitales y de las economías de plataforma altamente demandas), la suspensión de los y las trabajadoras que no podían llevar adelante sus actividades a través del teletrabajo o el desempleo de otros durante los períodos de cuarentena (Cifuentes-Faura, 2020) serían expresión de los efectos económicos de la emergencia sanitaria. Se señala que los apoyos estatales fueron otorgados a quienes contaban con empleo formal. Ello lleva a algunos textos a identificar el cuestionamiento de las políticas de inmovilidad como estrategia de aquellos que no se encuentran dentro del mercado laboral y que precisan salir a trabajar por carecer de recursos económicos (Vecchio y Tiznado-Aitken, 2020), a pesar del riesgo que esto significa. En este sentido, el cuerpo en tanto recurso de supervivencia adquiere el carácter de territorio (Barbosa, 2020; Haesbaert, 2020). 


\begin{abstract}
A las reflexiones anteriores, es posible sumar el aporte de los trabajos que concentran su atención en las desigualdades que se desprenden de la educación a distancia impuesta por la situación de la pandemia. La literatura brasileña afirma, en primer lugar, que las diferencias de acceso a dispositivos tecnológicos llevan a la identificación de una brecha digital a nivel educativo. En segundo lugar, señala que la virtualidad genera una angustia compartida por familias y docentes que no siempre disponen de espacios y tiempos para responder a las demandas de la enseñanza. A la duplicación de las tareas de los y las docentes (ellos tienen que dividirse entre los cuidados familiares y el dictado de clases a través de plataformas virtuales), se añade la pérdida de la institución como espacio de encuentro, como lugar de transmisión de valores, experiencias y saberes. De esta forma, pareciera haber acuerdo en que la educación a distancia no puede reemplazar al espacio presencial. Se reconoce que la relación presencial garantiza la construcción colectiva, emocional y afectiva del conocimiento (Diniz, 2020; De Santana Filho, 2020; De Franca Filho et al., 2020).
\end{abstract}

\title{
Los cuidados y sus ambivalencias
}

Una de las cuestiones tratada de forma recurrente por la bibliografía es el hecho que la pandemia puso en evidencia el requerimiento de otorgar mayor relevancia a una ética de los cuidados (Lawson, 2007). Esta temática, incorporada en la agenda disciplinar por la geografía feminista, pondría en cuestión tanto la mirada geopolítica clásica como la perspectiva capitalista neoliberal que priorizaron históricamente la competencia por sobre la solidaridad económica y social (Vallejo, 2020; Springer, 2020).

Por un lado, se sostiene que las acciones estatales definieron la escala del hogar como el espacio privilegiado en el cual llevar a cabo el aislamiento social preventivo (Grandi, 2020; Oliveira, 2020). Este ámbito dejó de ser el espacio dedicado fundamentalmente a los cuidados, para también tornarse el de desarrollo de las actividades laborales y educativas. Esta resignificación también fue atravesada por la diferencia de género. En efecto, los análisis expresan que la pandemia supuso una recarga de labores sobre las mujeres que, atravesadas por diferencias de clase y la raza, experimentan tensiones a partir del solapamiento entre las tareas vinculadas a la maternidad, a los cuidados y al trabajo remunerado (Manzo y Minello, 2020). Mientras que desde las políticas de aislamiento preventivo el espacio del hogar es pensado como refugio, las mujeres que vivencian la violencia cotidiana en el espacio doméstico no lo perciben de esta manera (Cabrera-Barona y Carrión, 2020). Así, algunos trabajos sugieren comprender al espacio doméstico como un ámbito de construcción de subjetividades políticas, abierto y en disputa con el movimiento del mundo (Oliveira, 2020).

Otra cuestión abordada tiene que ver con la actuación de aquellos y aquellas trabajadoras que fueron visibilizados como responsables del cuidado de la salud y de la distribución de alimentos y que, al asumir estas responsabilidades, quedaron más expuestos al contagio (repartidores, empleados de la limpieza, enfermeras y médicos). Se entiende entonces que los trabajadores de los cuidados se insertan en una economía capitalista que, a partir de definir geografías desiguales, migran a países o ciudades donde se incorporan a mercados de trabajo flexibles, racializados y estigmatizados (Sparke y Anguelov, 2020).

Finalmente, algunos textos abordan la relación entre pandemia, cuidados y prácticas solidarias y afectivas. Así, se identifican las prácticas de distintas organizaciones (en 
América Latina, las barriales) que salieron a ofrecer apoyos en especial a las personas mayores en aquellos ámbitos que el Estado no ha llegado para paliar las carencias sanitarias y alimenticias (Conde, 2020).

\section{La espacialidad de la "nueva" normalidad: perspectivas futuras}

La magnitud de la crisis global producida por expansión del COVID-19 se presenta como punto de inflexión ante el cual se abren diferentes posibilidades futuras. En este marco varios autores y autoras se preguntan cómo se presentará el escenario político mundial: ¿̇habrá un cuestionamiento a la globalización, al capitalismo y al Estado tal como lo concebimos en la actualidad?

Desde la perspectiva de las relaciones internacionales, existe cierto consenso sobre la dificultad de darse un proceso de desglobalización. Según Saracho López (2020), tendrá lugar una reestructuración económica acompañada del aumento de la capacidad de acumulación de los centros de poder. Al mismo tiempo, "la elite política/económica de los Estados Unidos, encuentra una disputa real a su dominio hegemónico por su contraparte china (...) Sin embargo (...) dicha disputa solo reafirma el carácter práctico e instrumental del (...) sistema-mundo en sí.” (Saracho López, 2020:76).

Por su parte, Millán y Santander (2020) identifican tres respuestas posibles de los Estados ante las preocupaciones que forman parte de la agenda política global, como la mitigación del cambio climático, la movilidad humana, la protección de los refugiados o el control de pandemias. Estas respuestas serían la inercial, el repliegue y la cosmopolita. Mientras que la respuesta inercial no representaría grandes cambios respecto a la organización mundial actual (lo cual provocaría una "brecha de gobernanza" debido al carácter global de los fenómenos a atender y el carácter parcial e imperfecto de las respuestas estatales), el repliegue implicaría un cierre del Estado en sí mismo y una oposición a cualquier propuesta de transferencia de competencias a instituciones internacionales o supraestatales. Esta respuesta dificultará la posibilidad de entablar diálogos en relación a los temas de agenda señalados previamente. En relación a la tercera respuesta, la cosmopolita, Millán y Santander la conciben como la más apropiada para enfrentar adecuadamente pandemias globales como la del COVID-19. La respuesta cosmopolita se orienta a construir un escenario en que se busque acercar lo más posible la ciudadanía a la toma de decisiones a partir de la organización de una arquitectura multinivel (local-estatal-regional-global). En este marco, el sistema de gobernanza global no niega las identidades locales, pues se construye sobre la base de un Estado que asume la inclusión y el reconocimiento del otro a distintas escalas en sociedades "transnacionalizadas" (Millán y Santander; 2020:255).

La perspectiva de los estudios de la Geografía latinoamericana ofrece un único modelo de Estado futuro. Frente a las desigualdades socio-espaciales que visibilizó la pandemia, los textos de la región consideran necesario recuperar un Estado fuerte que, a contrapelo de las políticas neoliberales, se haga cargo de la gestión del territorio, de la infraestructura urbana y en particular al sistema de salud (Ramos, 2020; Zanotelli y Dota, 2020). 
Al pronóstico sobre el futuro de la globalización y el Estado se suma la pregunta por el futuro del capitalismo. En general, la crisis producida por la pandemia ha llevado a visibilizar el alto costo ambiental del actual modelo capitalista (Cooper y Alderman, 2020; Ioannides y Gyimóthy, 2020) y a contribuir a ampliar la conciencia ambiental (Galvani et al., 2020).

Las posturas respecto al futuro de la relación entre capitalismo y ambiente se dividen entre las perspectivas pesimistas que predicen un retorno a formas de producción extractivista (Everingham y Chassagne, 2020; Haywood, 2020; Prideaux et al., 2020) y las posturas optimistas que pronostican la apertura hacia modelos económicos más sustentables (Ateljevic, 2020; Benjamin et al., 2020). Desde esta última perspectiva, se plantea la posibilidad de reactivación en términos de economías diversas, a través del desarrollo de modelos no capitalistas, de mercados alternativos o de formas de organización comunitarias (Cave y Dredge, 2020).

Una vez más, la escala local es idealizada y vista como clave en la reconstrucción económica y en la instauración de modelos más justos. Se considera que esta es una escala privilegiada para activar otros modos de vincularse con la naturaleza, dando impulso a acciones colectivas, ecológicas, sustentables y comunitarias, con lazos de apoyo mutuo y solidaridad social e interterritorial que podrían derivar en nuevas formas de apropiación y de toma de decisión sobre los territorios (Ateljevic, 2020; Barbosa, 2020; Benjamin et al., 2020; Blanco et al., 2020; Boira, 2020; Castilho, 2020; Cataia, 2020; Cheer, 2020; Cooper y Alderman, 2020; Everingham y Chassagne, 2020; Haesbaert, 2020; Haywood, 2020; Higgins-Desbiolles, 2020; López, 2020; Da Silva Medeiros, 2020; Méndez, 2020; Neto y Castro, 2020; Roxo, 2020; Rowen, 2020; Said y Silva, 2020; Silva et al, 2020; Tapia y Bouza, 2020; Tremblay-Huet, 2020; Tomassini y Cavagnaro, 2020; Vegas Gallo, 2020; Zapata, 2020).

Por último, el posicionamiento de varios autores y autoras respecto de la disparidad entre el Norte y Sur Global, y la caracterización del capitalismo actual como neocolonial, también tiene implicancias en cuanto a la forma de abordar algunos de los desafíos que se presentan a futuro (Carr, 2020; Evernigham y Chassange, 2020; Renaud, 2020). Así, desde una perspectiva en clave Sur se identifican una serie de requerimientos específicos a corto y mediano plazo. En el corto plazo, y en términos económicos, se plantea la necesidad de transferir recursos hacia los sectores más vulnerables (Arrais et al., 2020; Silva, 2020). En términos sanitarios, se sugiere prestar atención a la distribución espacial de la población y a los equipamientos de salud (Barbosa, 2020; Castilho, 2020; Cardoso Rodrigues y Cardoso Rodrigues, 2020; Fortes et al., 2020; Lima et al., 2020; Lima e Silva et al., 2020; Magalhaes et al., 2020; Matsumoto et al., 2020; Machado et al., 2020; Pereira Caldas, et al., 2020; Said y Silva, 2020; Silva y Muniz, 2020; Ramos, 2020; Ribeiro, 2020; Rocha, 2020; Wagner et al., 2020; Zanotelli y Dota, 2020).

En el mediano y largo plazo se recomienda promover políticas de soberanía, autonomía, autogestión, iniciativas de comercio local y circuitos cortos (Alentejano, 2020; Mello-Théry y Théry, 2020; Rodrigues, 2020). De este modo, sería posible construir territorios más igualitarios y ambientalmente respetuosos (Barbosa, 2020; Bernardes, et al., 2020; Castilho, 2020; González Marín, 2020; Gutiérrez Hernández, 2020; Harvey, 2020; Montemerli, 2020; Nel-lo, 2020; Porto-Gonçalves, 2020a; Rocha, 2020; Sánchez, 2020; Tapia y Bouza, 2020; Vegas Gallo, 2020; Zanotelli y Dota, 2020; Zapata, 2020). 
Por su lado, Barbosa (2020) y Castilho (2020) sugieren que las organizaciones de la sociedad civil, profesionales de la salud y los movimientos sociales podrían proponer la creación de una amplia agenda de protección y cuidados orientada hacia los sectores más vulnerables. La idea de los cuidados podría extenderse a la protección de la naturaleza para, desde allí, resguardar también a la sociedad (Vegas Gallo, 2020). Preocupaciones de esta índole, podrían contribuir a concebir una biopolítica ya no centrada en el control y la vigilancia, sino en los afectos (Haesbaert 2020).

Un último conjunto de textos propone potenciar las luchas anticapitalistas y pensar propuestas que vayan más allá del keynesianismo, dirigiéndose hacia el socialismo (Algebaile y Oliveira, 2020; Machado et al., 2020; Porto-Gonçalves, 202ob). Por su parte, Neto y Castro (2020), plantean la imposibilidad de sostener una solidaridad de cuño nacionalista y belicista que encubra la lucha de clases y no atienda los conflictos globales de interés. En su lugar, prefieren hablar de una solidaridad revolucionaria dirigida a la clase trabajadora que busque la transformación social del régimen capitalista y de la ideología neoliberal.

\section{Los desafíos para las prácticas turísticas}

La mayoría de los artículos publicados sobre el tema del turismo conciben a la actividad como uno de los vectores de contagio (Menchero Sánchez, 2020). Esta condición es inescindible de su caracterización como expresión específica de acumulación del capitalismo neoliberal (Benjamin et al., 2020). Se afirma que la pandemia no es el único y directo causante de la crisis actual en el sector turístico, pero sí ha contribuido a poner al descubierto y a agravar dramáticamente una serie de problemas preexistentes (Cave y Dredge, 2020; Mostafanezhad, 2020).

En primer lugar, se señala la no sustentabilidad de un modelo que tiene como rasgos característicos la masividad (overtourism). Se hace hincapié en los efectos adversos del turismo masivo debido al impacto ambiental que provoca (emisión de gases como producto directo de los medios de transporte aéreo, por ejemplo) o debido a la superpoblación de los destinos de turistas (ello lleva a las poblaciones locales a evitar los sitios frecuentados por estos visitantes) (Cooper y Alderman, 2020; Nepal, 2020; Romagosa, 2020; Tremblay-Huet, 2020). En este contexto, los cruceros aparecen como emblema de ese cuestionable modelo de turismo, altamente rentable para algunos sectores del capitalismo trasnacional (Higgins-Desbiolles, 2020; Renaud, 2020).

En segundo lugar, se plantea la necesidad de reconsiderar la excesiva confianza que se ha construido en torno a esta actividad como medio privilegiado de desarrollo económico (Cave y Dredge, 2020; Everingham y Chassagne, 2020). En este marco, se sostiene la necesidad de revisar las condiciones de precariedad laboral a las que son sometidos los trabajadores y que la parálisis de la actividad puso en evidencia.

En tercer lugar, se cuestionan los discursos en boga, como aquellos referidos a un "turismo responsable" o "sostenible", difundidos fundamentalmente organismos internacionales como la Organización Mundial del Turismo (Higgins-Desbiolles, 2020; Romagosa, 2020) y que apenas encuentran eco en experiencias concretas. 
Los artículos repasan diferentes desafíos a enfrentar en un mundo post COVID-19 a corto y mediano plazo. A corto plazo, y en plena crisis del sector, algunos autores y autoras sostienen que debido al lugar que se le otorga al turismo en muchas economías, probablemente habrá una presión por reactivar la actividad lo más rápido posible (Brouder, 2020; Everingham y Chassange, 2020; Hall et al., 2020). Otras lecturas se muestran preocupadas por el modo en que se repartirán los recursos estatales para el rescate o apoyo de actividad turística (Mostafanezhad, 2020). Teniendo en cuenta la heterogeneidad del sector, una pregunta que atraviesa algunos de los artículos es ¿cómo generar condiciones equitativas para la reactivación del turismo que no termine beneficiando a los mismos de siempre?

A mediano y largo plazo, las miradas se vuelcan hacia diferentes caminos posibles que podría tomar el turismo luego de su reactivación (Brouder, 2020). Ante la hiperglobalización del mundo, en la que el turismo juega un rol fundamental, un primer obstáculo señalado es la dificultad para que se materialicen consensos políticos sin acuerdos multilaterales para que se den transformaciones reales a nivel global.

Las miradas de la sustentabilidad, de las teorías regenerativas (Ateljevic, 2020), del decrecimiento (Renaud, 2020) y el auge de diversas versiones de un Green New Deal (Haywood, 2020), junto a la introducción de una perspectiva esperanzadora (Pernecky, 2020), son vistas en algunos textos no solo como faros que orientarían la construcción de una crítica al modelo de turismo actual, sino que también podrían acompañar el desarrollo de formas de turismo centradas menos en la ganancia y más en el beneficio para las comunidades destinos.

Tomassini y Cavagnaro (2020) consideran que los cambios en la actividad se percibirán, primeramente, a escala local, en la medida que posiblemente se estimulará el turismo de proximidad. Esto resultará una oportunidad para que las comunidades locales se cuestionen su inserción en el mercado turístico y mejoren su poder de negociación (Renaud, 2020), defendiendo sus intereses y derechos en la búsqueda de un turismo orientado a la justicia social y ambiental (Higgins-Desboilles, 2020).

Actores del sector vinculados entre sí, junto a un conjunto de investigadores, están constituyendo un grupo informal que apuntan a desarrollar lo que denominan "turismo transformacional”. Ellos procuran traer a colación teorías y aportes conceptuales alternativos que provienen de disciplinas no vinculadas usualmente a las ciencias sociales (Ateljevic, 2020; Cheer, 2020). Así, algunos artículos consideran que el turismo puede producir cambios en las actitudes y prácticas de los turistas. A través de la incorporación de otras concepciones como el turismo lento, el turismo consciente, o de la incorporación del paradigma del mindfulness, es posible contribuir a generar un cambio entre quienes lo practican (Benjamin et al., 2020; Stankov et al., 2020). El concepto de turismo transformacional que se nutre de estas nociones procura que la actividad deje de ser concebida únicamente como un sector de la economía o como práctica superficial y hedonista, para orientarse a construir un mundo mejor (Rowen, 2020).

A la hora de configurar escenarios futuros para el turismo (Carr, 2020), otros autores y autoras recuperan cosmovisiones no occidentales como el paradigma del Buen Vivir (Everingham y Chassagne, 2020). Las lecturas realizadas desde enfoques más vinculados a lo subjetivo también adquieren cierto potencial como línea de indagación, para sumarse 
a otros abordajes más estructurales. Esto se traduce, por ejemplo, en conceptos como el duelo colectivo o duelo ecológico (Crossley, 2020), la angustia ambiental o aspectos relacionados con la creación de una conciencia ambiental global (Galvani et al., 2020).

Edelheim (2020) sugiere que el desafío para los ámbitos académicos es el de superar la lectura crítica para participar activamente en las transformaciones que se debaten en el papel. Desde su lugar como formadores de actores clave del sector, los y las académicas pueden contribuir no solo al des-aprendizaje de los lineamientos del modelo de turismo actual. sino que también pueden colaborar en la incorporación de nuevos enfoques y valores orientados al cambio.

Una pregunta que atraviesa a varios de los artículos es si la movilidad global será distinta en el mundo postpandemia. Se reconoce que la utilización de las telecomunicaciones podría impactar en las futuras formas de trabajo y negocios, al mismo tiempo que los viajes internacionales podrían tener cierta demora en ser reactivados (y probablemente no vuelvan a alcanzar los niveles de los últimos años). En este contexto, se promoverían viajes cortos asociados al desarrollo de turismo de cercanía o a la visita a áreas con población dispersa (Ioannides y Gyimóthy, 2020; Romagosa, 2020). A partir de estos indicios, limitar la movilidad global y favorecer la local aparece como una opción. Se apuntaría así a un desarrollo sostenible en oposición al incremento en la capacidad de movimiento que suele favorecer no solo las relaciones globalizadas, sino también un mayor consumo de recursos ambientales (Higgins-Desbiolles, 2020; Renaud, 2020; Stankov et al., 2020).

\section{Aportes de la geografía}

Desde distintos lugares de enunciación geógrafos y geógrafas consideran que la pandemia del COVID-19 posee una componente espacial que interpela a la disciplina a realizar aportes para su análisis y comprensión. Así, de acuerdo con Lois González (2020:2) mientras que "la crisis generada por la Gripe española fue un acontecimiento histórico, el Coronavirus ya es geográfico." Del mismo modo, Ricardo Méndez (2020:1) considera que es necesario "promover una geografía ciudadana atenta a investigar el impacto local y la vida cotidiana de estos procesos, su desigual intensidad social y territorial, junto a sus posibles alternativas".

Algunos textos consideran que la disciplina puede ofrecer su instrumental técnico para la interpretación de la pandemia, de hecho, este es el planteo de la Editorial de la Revista Posición No3. En ella se afirma que la Geografía puede contribuir con la captura, sistematización y análisis (monitoreos en tiempo real y prospecciones) de la información, así como también con la elaboración de propuestas destinadas a gestionar el territorio de modo más eficiente. Otros textos recomiendan hacer uso del bagaje de la tradición disciplinar para "la comprensión del poder de la ideología en la producción de lecturas del mundo" (Karol y Silva, 2020:47). En rigor, pareciera haber un acuerdo en que la Geografía tiene cosas para decir, para hacer y para aportar bajo esta coyuntura.

La literatura señala dos campos de trabajo que pueden realizar aportes a la gestión sanitaria del COVID-19 y a la reorganización espacial postpandemia. Mientras que el primer dominio corresponda a la Geografía Médica, el segundo tiene que ver con la planificación territorial. 
Sobre una amplia coincidencia en el papel jugado por el capitalismo neoliberal, la globalización, la red de transportes y la interconexión de las ciudades de diferente jerarquía urbana en la expansión de la dolencia, los estudios en Geografía Médica producidos en Argentina y Brasil han ofrecido elementos para interpretar la distribución y difusión espacio-temporal del COVID-19 a nivel estatal o regional. Desde el punto de vista de Ribeiro (2020:17) "el raciocinio geográfico es una estrategia que puede contribuir a entender cuáles son las variables territoriales que propician la propagación del virus, reforzando así, los modelos epidemiológicos ya en uso".

En este marco, se otorga importancia el empleo de cartografía, de datos georreferenciados, de modelos estadísticos y de difusión, potencializando el uso de los Sistemas de Información Geográfica y otras Tecnologías de la Información y Comunicación (Barbosa y Hernández García, 2020; Buzai, 2020; García de León Loza, 2020; Martinuci et al., 2020b; Pereira Caldas et al., 2020; Romero et al., 2020; Santana Juárez et al., 2020; Santos Júnior et al., 2020; Soares et al., 2020; Sotela y Mayorga, 2020; Vicente Ferreira et al., 2020; Aleixo et al., 2020; Lima e Silva et al., 2020; Magalhães et al., 2020; Vicente Ferreira, 2020). Así, el análisis cuantitativo y cartográfico se ha orientado a identificar las desigualdades socioespaciales y las vulnerabilidades preexistentes (Alarcón y Juárez Gutiérrez, 2020; Cardoso Rodrigues y Cardoso Rodrigues, 2020; Catão et al., 2020; Juárez, 2020; Martinuci et al., 2020a; Neto, 2020; Nossa, 2020; Wagner et al., 2020), a construir indicadores de sustentabilidad, vulnerabilidad y riesgo (Gonzaga et al., 2020; Nascimento Júnior et al., 2020; Salinas y Nochebuena, 2020; Ramalho Barros et al., 2020; Soares Da Silva, et al., 2020) y a analizar la percepción del riesgo del COVID-19 en términos de miedo y aislamiento (Bezerra et al., 2020; Gomes de Aguiar et al., 2020).

Los trabajos que abordan la planificación territorial se han propuesto reflexionar sobre las características de las aglomeraciones urbanas, la distribución y movilidad de las personas en el espacio (Domínguez-Mújica, 2020; Dumont, 2020; Galvani et al., 2020; Ioannides y Gymóthy, 2020; Renaud, 2020; Tremblay-Huet, 2020). Así, consideran que habrá que pensar formas alternativas de intervención y gestión orientadas a servir a la sociedad y, en particular, a satisfacer los requerimientos sanitarios. Desde la perspectiva de Rocha (2020:11) "son necesarias políticas públicas (...) pensadas en terminos éticos y a la luz de una inteligencia territorial apta para atender las condiciones de vida de sus poblaciones, y no para afirmar políticas fragmentadas, privatizantes, clientelistas e individualizadas". Esto supondrá revisar los modelos de urbanización (González Marín, 2020; Simão, 2020), de transporte y la logística de bienes y servicios básicos (Boira, 2020), así como planes estratégicos (Ateljevic, 2020; López, 2020; Lozano Valencia, 2020) a partir de una ética territorial que, reuniendo otras éticas culturales, políticas, sociales, económicas y ambientales, se constituya en una herramienta performativa multiescalar para actuar en el espacio.

Esta reflexión lleva a los y las autoras a considerar que las herramientas de interpretación y gestión territorial que ofrece la disciplina no solo permiten concientizar a la sociedad sobre la difusión de la dolencia, sino que también contribuyen a gerenciar la crisis sanitaria y a evitar otras futuras (Cardoso et al., 2020). En este marco, se reconoce la relevancia del conocimiento disciplinario en Latinoamérica puede acompañar el fortalecimiento del Estado y proveer herramientas para la formulación de políticas públicas (Arrais et al., 2020; Barbosa, 2020; Canuto et al., 2020; Castilho, 
2020; Castanho, 2020; Cataia, 2020; Frigotto, 2020; González Marín, 2020; Goveia, 2020; Lima e Silva et al., 2020; Lozano Valencia, 2020; Mello-Théry y Théry, 2020; Nel-lo, 2020; Ribeiro, 2020; Said y Silva, 2020; Silva, 2020; Soares da Silva et al., 2020; Porto-Gonçalves, 2020a,b; Rocha, 2020; Rodrígues y Azevedo, 2020; Rossi y Silva; 2020; Zanotelli y Dota, 2020).

\section{Las geografías académicas futuras}

En el mes de abril del 2020 la editorial de la Revista Progress in Human Geography (Castree et al., 2020) consideraba que la pandemia abría la posibilidad de reflexionar sobre los contenidos de las agendas de investigación de la disciplina. Ello podría suponer repensar las herramientas que poseemos para describir, explicar y evaluar la crisis desplegada, colocando en primer plano la desigualdad espacio-temporal. En este sentido, quizás la experiencia del COVID-19 permita evaluar la posibilidad de recuperar las perspectivas clásicas de la disciplina (como la teoría de la difusión de Haggerstrand o los aportes de Max Sorre ${ }^{3}$ en relación a geografía de la salud) y ponerlas en diálogo con los procesos en curso. Quizás precisamos tensionar las teorías geográficas dominantes, a partir de desarrollar una geografía sensible y corporificada que explicite su sentido existencial y que esté abierta a las cuestiones de métodos propuestas por los estudios feministas de valorización de saberes situados, corporificados, parciales, localizados y críticos. A su vez, los aportes de las ontologías relacionales nos permitirían abordar los vínculos entre humanos y no humanos que tienen lugar en el proceso de expansión de un virus como el COVID-19, evitando recurrir a metáforas belicistas que acaban derivando en el uso de estrategias preventivas de carácter militar.

Simultáneamente, el interés por multiplicar las voces académicas desde las cuales se construyen interpretaciones sobre la forma en que los procesos de expansión del virus tienen lugar, podría contribuir a formular políticas menos homogéneas y más adecuadas a las condiciones geográficas, económicas y culturales específicas. De hecho, la expansión de la pandemia en África es una muestra de ello. En efecto, según Oppong (2020), fueron las condiciones habitualmente concebidas como propias del subdesarrollo (escasos medios de transporte, conectividad rural limitada, agricultura de subsistencia y una urbanización relativamente baja) las que habrían contribuido a proteger a los habitantes rurales de este continente de la diseminación de la pandemia global en estos ámbitos.

En síntesis, podríamos afirmar que la emergencia sanitaria global aparece como una oportunidad para que la Geografía siga (re)pensándose a sí misma, en la búsqueda de ofrecer explicaciones, caminos, y de contribuir en la construcción de escalas y territorios alternativos.

3 Al respecto, ver la Intervención de Mónica Arroyo en el Seminario Desafíos Territoriales frente a la Pandemia COVID-19, Perspectivas desde América Latina, el día 9 de setiembre de 2020. Este seminario fue organizado por el Instituto de Geografía de la Universidad de Buenos Aires y se transmitió por el canal YouTube de la Facultad de Filosofía y Letras de dicha Universidad: https://www.youtube.com/watch?v=LOPzxRul744\&t=963s 


\section{Q Bibliografía}

》 Abizaid, C., Collado Panduro, L. A. y Egusquiza, S. G. (2020). Pobreza y medios de subsistencia en la Amazonía Peruana en tiempos de la Covid-19. Journal of Latin American Geography, 19(3), 202-214. Recuperado de https://muse.jhu.edu/ article/760940

》 Agamben, G. (2020). La invención de una pandemia. El Cohete a la Luna. Recuperado de: https://www.elcohetealaluna.com/la-invencion-de-una-epidemia

" Agnew, J. (2020). American "Populism" and the Spatial Contradictions of US Government in the Time of COVID-19. Geopolitica(s). Revista de Estudios Sobre Espacio y Poder, 11(Especial), 15-23. Recuperado de: https://doi.org/10.5209/ geop.69018

» Alarcón, I. V. y Juárez Gutiérrez, M.C. (2020). México: Las enfermedades crónico degenerativas (diabetes melitus e hipertensión) y la vulnerabilidad ante el COVID-19. Posición, 3, 1-15. Recuperado de: https://716132a6-9cf5-45de-baee6a15e46210f7.filesusr.com/ugd/df634b_78a496c95da44c4f8254a2b062088c70. pdf

» Aleixo, N. C. R., Silva Neto, J. C. A. da y Catão, R. de C. (2020). A difusão temporo-espacial da Covid-19 no Amazonas. Hygeia - Revista Brasileira de Geografia Médica e da Saúde, 336-348. Recuperado de: https://doi.org/10.14393/ Hygeia0054536

》 Alentejano, P. R. R. (2020). Reforma agrária, caos urbano, agronegócio e pandemia. Revista Tamoios, 16(1), 32-38. Recuperado de: https://doi. org/10.12957/tamoios.2020.50242

" Algebaile, E. y Oliveira, F. J. G. de. (2020). A superação do capitalismo em questão: Com que prática, em qual direção? Espaço e Economia, 17. Recuperado de: https://doi.org/10.4000/espacoeconomia.11131

»Arrais, T. A., Oliveira, A. R. de, Alencar, D. P., Salgado, T. R., Viana, J. L. y Miranda, A. F. (2020). Pandemia covid-19: 0 caráter emergencial das transferências de renda direta e indireta para a população vulnerável do estado de Goiás. Espaço e Economia, 18. Recuperado de: https://doi.org/10.4000/espacoeconomia.13734

"Ateljevic, I. (2020). Transforming the (tourism) world for good and (re)generating the potential "new normal". Tourism Geographies, 22(3), 467-475. Recuperado de: https://doi.org/10.1080/14616688.2020.1759134

» Azeredo Rodrigues, L. (2020). Transporte aéreo de passageiros e o avanço da Covid-19 no Brasil. Hygeia - Revista Brasileira de Geografia Médica e da Saúde, 193-201. Recuperado de: https://doi.org/10.14393/Hygeia0054407

"Barbosa, J. L. (2020). Por uma quarentena de direitos para as favelas e as periferias! Espaço e Economia, 17. Recuperado de: https://doi.org/10.4000/ espacoeconomia.10274

» Barbosa, J. S. y Hernández García, R. (2020). El Coronavirus del año 2020: Efectos y difusión espacial de esta pandemia en Puerto Rico y el Caribe. Posición, 3, 1-20. Recuperado de: https://716132a6-9cf5-45de-baee-6a15e46210f7.filesusr.com/ ugd/df634b_bee2f72a78cf4538a4a692c55f175fa9.pdf 
» Benites, G y Begginton, A. (2020) Political settlements and the risk governance of Covid-19: mining, risk and territorial control in Peru. Journal of Latin American Geography, 19(3), 215-223. Recuperado de: https://muse.jhu.edu/article/760941

"Benjamin, S., Dillette, A. y Alderman, D. H. (2020). "We can't return to normal": Committing to tourism equity in the post-pandemic age. Tourism Geographies, 22(3), 476-483. Recuperado de: https://doi.org/10.1080/14616688.2020.1759130

》 Bernardes, J. A., Arruzzo, R. C., y Monteiro, D. M. L. V. (2020). Geografia e covid-19: neoliberalismo, vulnerabilidades e luta pela vida. Revista Tamoios, 16(1), 188-205. Recuperado de: https://doi.org/10.12957/tamoios.2020.50645

» Bezerra, A. C. V., Silva, C. E. M. da y Soares, F. R. G. (2020). Percepção sobre o isolamento social no contexto da pandemia de Covid-19 no estado de Pernambuco, Brasil. Hygeia - Revista Brasileira de Georafia Médica e da Saúde, 143-152. Recuperado de: https://doi.org/10.14393/Hygeia0054397

» Blanco, I., Gomà, R. y Nel-lo, O. (2020). Por una ofensiva solidaria. La acción colectiva ante la epidemia. Reflexiones sobre la crisis COVID-19. Asociación Española de Geografía. Recuperado de: https://www.age-geografia.es/site/wpcontent/uploads/2020/04/oriol-v2.pdf

» Blue, G. y Rock, M. (2020). Genomic trans-biopolitics: Why more-thanhuman geography is critical amid the COVID-19 pandemic. Dialogues in Human Geography, 10(2), 287-290. Recuperado de: https://doi. org/10.1177/2043820620935660

» Boira, J.V. (2020). 10 Lecciones de la crisis del Covid-19 para el sistema de transporte y logística español. Un análisis de urgencia. Reflexiones sobre la crisis COVID-19. Asociación Española de Geografía. Recuperado de: https://www.agegeografia.es/site/wp-content/uploads/2020/03/boira-v1.pdf

》 Borja, D. y Buitrón Cañadas, V. (2020) Si, la normalidad es el problema: inequidad, exclusión y fuerza estatal en la crisis de la Covid-19 en Guayaquil. Journal of Latin American Geography, 19(3), 224-233. Recuperado de https://muse.jhu.edu/ article/760942/

»Brice, J. (2020). Charting COVID-19 futures: Mapping, anticipation, and navigation. Dialogues in Human Geography, 10(2), 271-275. Recuperado de: https://doi. org/10.1177/2043820620934331

»Bringel, B. (2020). Geopolítica de la pandemia, escalas de la crisis y escenarios en disputa. Geopolítica(s). Revista de estudios sobre espacio y poder, 11(Especial), 173-187. Recuperado de: https://doi.org/10.5209/geop.69310

» Brouder, P., Teoh, S., Salazar, N. B., Mostafanezhad, M., Pung, J. M., Lapointe, D., Desbiolles, F. H., Haywood, M., Hall, C. M. y Clausen, H. B. (2020). Reflections and discussions: Tourism matters in the new normal post COVID-19. Tourism Geographies, 22(3), 735-746. Recuperado de: https://doi.or $\mathrm{g} / 10.1080 / 14616688.2020 .1770325$

» Buzai, G. D. (2020). De Wuhan a Luján. Evolución espacial del COVID-19. Posición, 3, 1-21. Recuperado de: https://716132a6-9cf5-45de-baee-6a15e46210f7.filesusr. com/ugd/df634b_07b73e827efd4c439662ea589ecf1250.pdf

" Cabrera-Barona, P. y Carrión, A. (2019). Voiding Public Spaces, enclosing domestic places: place attachment at the onset of the pandemic in Quito. Journal of Latin American Geography, 19(3), 234-239. Recuperado de: https://digitalcommons.Isu. edu/jlag/vol19/iss3/16/ 
》Campos, L. P. y Lins, T. (2020). Pandemia à Portuguesa: Um relato sobre o Covid-19 em Portugal. Espaço e Economia, 17. Recuperado de. https://doi. org/10.4000/espacoeconomia.10369

" Canuto, P. J., Lima, L. de S., Barbosa, H. C. V. y Bezerra, K. A. (2020). Repercussões do isolamento social diante da pandemia Covid-19: abordando os impactos na população. Hygeia - Revista Brasileira de Geografia Médica e da Saúde, 122-131. Recuperado de: https://doi.org/10.14393/Hygeia0054398

" Cardoso Rodrigues, J. y Cardoso Rodrigues, J. (2020). Condições de desigualdades e vulnerabilidades socioespaciais em cidades da Amazônia Paraense: elementos promovedores da expansão e dispersão da Covid-19? Hygeia - Revista Brasileira de Geografia Médica e da Saúde, 132-142. Recuperado de: https://doi.org/10.14393/Hygeia0054603

»Cardoso, P. V., Seabra, V. D. S., Bastos, I. B. y Porto Costa, E. D. C. (2020). A importância da análise espacial para tomada de decisão: um olhar sobre a pandemia de covid-19. Revista Tamoios, 16(1), 125-137. Recuperado de: https:// doi.org/10.12957/tamoios.2020.50440

»Carr, A. (2020). COVID-19, indigenous peoples and tourism: A view from New Zealand. Tourism Geographies, 22(3), 491-502. Recuperado de: https://doi.or $\mathrm{g} / 10.1080 / 14616688.2020 .1768433$

》 Castanho, A.R. (2020). La pertinencia de la planificación estratégica común en tiempos de Covid-19. Reflexiones sobre la crisis COVID-19. Asociación Española de Geografía. Recuperado de: https://www.age-geografia.es/site/wp-content/ uploads/2020/03/rui-alexandre-v1.pdf

" Castilho, D. (2020). Um vírus com DNA da globalização: 0 espectro da perversidade. Espaço e Economia, 17. Recuperado de: https://doi.org/10.4000/ espacoeconomia.10332

» Castree N, Amoore L, Hughes A, Laurie N, Manley D y Parnell S. (2020). Boundless contamination and progress in Geography. Progress in Human Geography, 44(3), 411-414. Recuperado de: doi:10.1177/0309132520920094

》 Cataia, M. (2020). Civilização na encruzilhada: globalização perversa, desigualdades socioespaciais e pandemia. Revista Tamoios, 16(1), 232-245. Recuperado de: https://doi.org/10.12957/tamoios.2020.50742

》 Catão, R. de C., Ribeiro, F. A. S., Veltem, C. da P. C. de C., Freitas, M. H. de y Chrisóstomo, F. C. (2020). Difusão espacial da Covid-19 no Espírito Santo: uma abordagem inicial. Hygeia - Revista Brasileira de Geografia Médica e da Saúde, 349-360. Recuperado de:https://doi.org/10.14393/Hygeia0054639

"Cave, J. y Dredge, D. (2020). Regenerative tourism needs diverse economic practices. Tourism Geographies, 22(3), 503-513. Recuperado de: https://doi.or $\mathrm{g} / 10.1080 / 14616688.2020 .1768434$

»Cheer, J. M. (2020). Human flourishing, tourism transformation and COVID-19: A conceptual touchstone. Tourism Geographies, 22(3), 514-524. Recuperado de: https://doi.org/10.1080/14616688.2020.1765016

»Chen, B., Marvin, S. y While, A. (2020). Containing COVID-19 in China: Al and the robotic restructuring of future cities. Dialogues in Human Geography, 10(2), 238241.Recuperado de: https://doi.org/10.1177/2043820620934267

»Cifuentes-Faura, J. (2020). Crisis del coronavirus: Impacto y medidas económicas 
en Europa y en el mundo. Espaço e Economia, 18. Recuperado de: https://doi. org/10.4000/espacoeconomia.12874

"Conde, M. (2020). Brazil in the Time of Coronavirus. Geopolítica(s). Revista de Estudios Sobre Espacio y Poder, 11(Especial), 239-249. Recuperado de: https://doi. org/10.5209/geop.69349

" Cooper, J. A. y Alderman, D. H. (2020). Cancelling March Madness exposes opportunities for a more sustainable sports tourism economy. Tourism Geographies, 22(3), 525-535. Recuperado de: https://doi.or $\mathrm{g} / 10.1080 / 14616688.2020 .1759135$

»Crossley, É. (2020). Ecological grief generates desire for environmental healing in tourism after COVID-19. Tourism Geographies, 22(3), 536-546. Recuperado de: https://doi.org/10.1080/14616688.2020.1759133

" Cupples, J. (2020). Love in the time of Covid-19: Or, Nicaragua, the Strange Country where childern still go to school. Journal of Latin American Geography, 19(3), 323-333. Recuperado de: https://digitalcommons.Isu.edu/jlag/vol19/ iss $3 / 28 /$

»Da Silva Medeiros, J. F. (2020). A Pandemia e seus (des)caminhos. Espaço e Economia, 18. Recuperado de: https://doi.org/10.4000/espacoeconomia.13141

"Datta, A. (2020). Self(ie)-governance: Technologies of intimate surveillance in India under COVID-19. Dialogues in Human Geography, 10(2), 234-237. Recuperado de: https://doi.org/10.1177/2043820620929797

»De França Filho, A. L., Da França Antunes, C. y Campos Couto, M. A. (2020). Alguns apontamentos para uma crítica da EaD na educação brasileira em tempos de pandemia. Revista Tamoios, 16(1), 16-31. Recuperado de: https://doi. org/10.12957/tamoios.2020.50535

» De Santana Filho, M. M. (2020). Educação geográfica, docência e o contexto da pandemia covid-19. Revista Tamoios, 16(1), 3-15. Recuperado de: https://doi. org/10.12957/tamoios.2020.50449

» Diniz, N. (2020). Reestruturação do trabalho docente e desigualdades educacionais em tempos de crise sanitária, econômica e civilizatória. Revista Tamoios, 16(1), 138-144. Recuperado de: https://doi.org/10.12957/ tamoios.2020.50253

»Domínguez-Mújica, J. (2020). Repensar la movilidad humana ante la pandemia del Covid-19. Reflexiones sobre la crisis COVID-19. Asociación Española de Geografía. Recuperado de: https://www.age-geografia.es/site/wp-content/uploads/2020/03/ josefina-dominguez-v1.pdf

» Dumont, G.F. (2020). Covid-19: Fim da geografia da hipermobilidade? Espaço e Economia, 18. Recuperado de: https://doi.org/10.4000/espacoeconomia.12926

》Edelheim, J. (2020). How should tourism education values be transformed after 2020? Tourism Geographies, 22(3), 547-554. Recuperado de: https://doi.or $\mathrm{g} / 10.1080 / 14616688.2020 .1760927$

》Everingham, P. y Chassagne, N. (2020). Post COVID-19 ecological and social reset: Moving away from capitalist growth models towards tourism as Buen Vivir. Tourism Geographies, 22(3), 555-566. Recuperado de: https://doi.or $\mathrm{g} / 10.1080 / 14616688.2020 .1762119$

»Everts, J. (2020). The dashboard pandemic. Dialogues in Human Geography, 10(2), 
260-264. Recuperado de: https://doi.org/10.1177/2043820620935355

»Farias, H. S. de. (2020). O avanço da Covid-19 e o isolamento social como estratégia para redução da vulnerabilidade. Espaço e Economia, 17. Recuperado de: https://doi.org/10.4000/espacoeconomia.11357

»Fortes, A., Oliveira, L. D. de y Sousa, G. M. de. (2020). A COVID-19 na Baixada Fluminense: Colapso e apreensão a partir da periferia metropolitana do Rio de Janeiro. Espaço e Economia, 18. Recuperado de: https://doi.org/10.4000/ espacoeconomia. 13591

» Frigotto, G. (2020). Empresários mais ricos do Brasil: A ignorância, o cinismo e a ganância que matam. Espaço e Economia, 17. Recuperado de: https://doi. org/10.4000/espacoeconomia.10852

" Galvani, A., Lew, A. A. y Perez, M. S. (2020). COVID-19 is expanding global consciousness and the sustainability of travel and tourism. Tourism Geographies, 22(3), 567-576. Recuperado de: https://doi.org/10.1080/14616688.2020.1760924

» García de León Loza, A. (2020) Indicadores básicos y tendencias espaciotemporales en 20 países por mortalidad COVID-19. Posición, 3, 1-23. Recuperado de: https://716132a6-9cf5-45de-baee-6a15e46210f7.filesusr.com/ugd/df634b_ f298339cc3d849c0bec880d4fbd0792d.pdf

» Gomes de Aguiar, V., Venâncio Ramos Júnior, D., Gonçalves Costa, K. y Sodré da Luz Silva Dias, R. (2020). Notificando o medo: cartografia e percepção da Covid-19 na malha rodoviária na porção norte dos vales dos rios Araguaia e Tocantins. Hygeia - Revista Brasileira de Geografia Médica e da Saúde, 153-163. Recuperado de https://doi.org/10.14393/Hygeia0054395

" Gómez Mendoza, J. (2020). “Confinavírico”. En pos de Rubén Lois: Sobre la geograficidad de la epidemia. Reflexiones sobre la crisis COVID-19. Asociación Española de Geografía. Recuperado de: https://www.age-geografia.es/site/wpcontent/uploads/2020/03/josefin-gm-v2.pdf

» Gonzaga, E. A. R., Lacerda, I. do C., Jesus, T. T. de y Lima, S. do C. (2020). Equidade, justiça social e cultura de paz em tempos de pandemia: um olhar sobre a vulnerabilidade municipal e a Covid-19. Hygeia - Revista Brasileira de Geografia Médica e da Saúde, 111-121. Recuperado de: https://doi.org/10.14393/ Hygeia0054569

» González Marín, A. (2020). Ampliación de aceras y carriles bici para evitar el contagio por Covid-19: El acercamiento a la ciudad peatonal. Reflexiones sobre la crisis COVID-19. Asociación Española de Geografía. Recuperado de: https://www. age-geografia.es/site/wp-content/uploads/2020/04/alicia-v1.pdf

»Goveia, L. A. M. (2020). A pandemia da Covid-19 na fronteira amazônica: uma análise preliminar nas cidades-gêmeas de Tabatinga e Leticia. Hygeia - Revista Brasileira de Geografia Médica e da Saúde, 221-230. Recuperado de: https://doi. org/10.14393/Hygeia0054531

» Grandi, M. D. S. (2020). Colapso e determinismo escalar em tempos pandêmicos: reflexões preliminares sobre a casa, o «isolamento social» e o déficit habitacional. Revista Tamoios, 16(1), 63-87. Recuperado de: https://doi.org/10.12957/ tamoios.2020.50511

» Gutiérrez Hernández, O. (2020). La Geografía frente a la crisis global COVID-19. Genealogía del colapso. Reflexiones sobre la crisis COVID-19. Asociación Española de Geografía. Recuperado de https://www.age-geografia.es/site/wp- 
content/uploads/2020/04/oliver-v1.pdf

»Hall, C. M., Scott, D. y Gössling, S. (2020). Pandemics, transformations and tourism: Be careful what you wish for. Tourism Geographies, 22(3), 577-598. Recuperado de: https://doi.org/10.1080/14616688.2020.1759131

》Haesbaert, R. (2020). Reflexões geográficas em tempos de pandemia. Espaço e Economia, 18. Recuperado de: https://doi.org/10.4000/espacoeconomia.11826

» Harvey, D. (2020). Política anticapitalista em tempos de COVID-19. En M. Davis et al., Coronavírus e a luta de classes (pp.13-25). Brasil: Terra sem Amos.

»Haywood, K. M. (2020). A post COVID-19 future - tourism re-imagined and reenabled. Tourism Geographies, 22(3), 599-609. Recuperado de: https://doi.or g/10.1080/14616688.2020.1762120

» Higgins-Desbiolles, F. (2020). Socialising tourism for social and ecological justice after COVID-19. Tourism Geographies, 22(3), 610-623. Recuperado de: https://doi. org/10.1080/14616688.2020.1757748

» Huish, R. (2020). Solidarity Trumps Fear: Cuba is a Model for Global Health in the21st Century. Journal of Latin American Geography, 19(3), 296-301. Recuperado de: https://digitalcommons.lsu.edu/jlag/vol19/iss3/24/

" loannides, D. y Gyimóthy, S. (2020). The COVID-19 crisis as an opportunity for escaping the unsustainable global tourism path. Tourism Geographies, 22(3), 624632. Recuperado de: https://doi.org/10.1080/14616688.2020.1763445

»Idler, A. y Hochmüller, M. (2020). Covid-19 in Colombia's Borderlands and the Western Hemisphere. Adding Instability to a Double Crisis. Journal of Latin American Geography, 19 (3), 280-288. Recuperado de: https://digitalcommons.Isu. edu/jlag/vol19/iss3/22/

» Juárez, M. V. S. (2020). COVID-19 en México: Comportamiento espacio temporal y condicionantes socioespaciales, febrero y marzo de 2020. Posición, 3, 1-27. Recuperado de: https://716132a6-9cf5-45de-baee-6a15e46210f7.filesusr.com/ ugd/df634b_96bb0dd9fa6b4621b96a2d722105f2bd.pdf

» Karol, E. y Silva, C. A. da. (2020). Da geografia da população à necropolítica: presentificação e disputas de sentido em tempos de coronavírus. Revista Tamoios, 16(1), 39-49. Recuperado de: https://doi.org/10.12957/ tamoios.2020.50375

"Lawson, V. (2007). Geographies of care and responsibility. Annals of the association of American Geographers, 97(1), 1-11.

» Leonard, K. (2020). Medicine lines and COVID-19: Indigenous geographies of imagined bordering. Dialogues in Human Geography, 10(2), 164-168. Recuperado de: https://doi.org/10.1177/2043820620934941

» Leopoldo, E. (2020). 0 mundo, a Amazônia e a região de fronteira no fio da navalha: O Sul e Sudeste do Pará em tempos da pandemia do coronavírus. Espaço e Economia, 18. Recuperado de: https://doi.org/10.4000/ espacoeconomia. 13707

» Lima e Silva, E., Miranda, M. J. de, Bezerra, A. B., Matos, K. F. R., y Gurgel, H. da C. (2020). Covid-19 na Região Integrada de desenvolvimento do Distrito Federal e entorno (RIDE): distribuição espacial e medidas sanitárias de contingência. Hygeia - Revista Brasileira de Geografia Médica e da Saúde, 287-297. Recuperado de: https://doi.org/10.14393/Hygeia0054621 
»Lima, S. do C., Fonseca, E. da S., y Santos, F. de O. (2020). Situação epidemiológica e difusão da Covid-19 pela rede urbana em Minas Gerais, Brasil. Hygeia - Revista Brasileira de Geografia Médica e da Saúde, 243-250. Recuperado de: https://doi.org/10.14393/Hygeia0054711

» Liu, X. y Bennett, M. M. (2020). Viral borders: COVID-19's effects on securitization, surveillance, and identity in Mainland China and Hong Kong. Dialogues in Human Geography, 10(2), 158-163. Recuperado de: https://doi. org/ $10.1177 / 2043820620933828$

» Lois González, R. (2020). Geografía (periodística) de la crisis del coronavirus. Geografía 2020. Generando discurso. Asociación Española de Geografía. Recuperado de: https://www.age-geografia.es/site/wp-content/uploads/2020/03/ generando-discurso-2.pdf

» Lois, M. (2020). Los Estados cierran sus territorios por seguridad... pero los virus están. Geopolítica(s). Revista de estudios sobre espacio y poder, 11(Especial), 293302. Recuperado de: https://doi.org/10.5209/geop.69370

» López, R.M. (2020). SPL del calzado y Coronavirus: Flexibilidad e innovación al servicio de la sociedad en tiempo récord. Reflexiones sobre la crisis COVID-19. Asociación Española de Geografía. Recuperado de: https://www.age-geografia. es/site/wp-content/uploads/2020/04/mecha-v1.pdf

» Loyer, B. y Giblin, B. (2020). ¿Qué mundo geopolítico después de 2020? Geopolítica(s). Revista de estudios sobre espacio y poder, 11(Especial), 115-126. Recuperado de: https://doi.org/10.5209/geop.69250

»Lozano Valencia, P. (2020). Algunas reflexiones a vuelapluma acerca del escrito de Rubén C. Lois González sobre la Geografía de la crisis del Coronavirus. Reflexiones sobre la crisis COVID-19. Asociación Española de Geografía. Recuperado de: https://www.age-geografia.es/site/wp-content/uploads/2020/03/ peio-lozano-v1.pdf

» Machado, B. S. M., Gonçalves, M. V. F., y Arcanjo, M. F. G. (2020). Neoliberalismo em tempos de coronavírus ou coronavírus em tempos de neoliberalismo? Espaço e Economia, 18. Recuperado de: https://doi.org/10.4000/espacoeconomia.12379

» Maddrell, A. (2020). Bereavement, grief, and consolation: Emotional-affective geographies of loss during COVID-19. Dialogues in Human Geography, 10(2), 107111. Recuperado de: https://doi.org/10.1177/2043820620934947

» Magalhães, S. C. M., Santos, F. de O., Lima, S. do C., y Fonseca, E. da S. (2020). Situação epidemiológica da transmissão da Covid-19 no norte de Minas Gerais, Brasil. Hygeia - Revista Brasileira de Geografia Médica e da Saúde, 80-87. Recuperado de: https://doi.org/10.14393/Hygeia0054629

» Manero, F. (2020). Una aproximación a los impactos geoeconómicos de la pandemia: el afianzamiento de la potencia industrial de china. Reflexiones sobre la crisis COVID-19. Asociación Española de Geografía. Recuperado de: https:// www.age-geografia.es/site/wp-content/uploads/2020/03/fernando-manero-v1-1. pdf

》 Marcu, S. (2020). La crisis del Coronavrius en el contexto europeo. Reflexiones geopolíticas. Geografía 2020. Generando discurso. Asociación Española de Geografía. Recuperado de: https://www.age-geografia.es/site/wp-content/ uploads/2020/03/generando-discurso-3.pdf

» Martinuci, O. da S., Janete Veltrini Fonzar, U., Francisco Pestana Biatto, J., Da 
Costa Francisco, I., Januário Augusto, I., y Diana Gazola, B. (2020a). Análise geográfica da Covid-19 em Maringá/PR. Hygeia - Revista Brasileira de Geografia Médica e da Saúde, 88-101. Recuperado de: https://doi.org/10.14393/ Hygeia0054628

» Martinuci, O. da S., Lima, V., Maria Endlich, Â., Cristiano Montanher, O., Grochoski Felini, M., Cristina Rigoldi, K., Milene Caraminan, L., Balieiro Crestani, R., Blaudt Lima da Silva, R., Henrique Sorato da Silva, G. y Rafaela Ferreira, M. (2020b). Dispersão da Covid-19 no estado do Paraná. Hygeia - Revista Brasileira de Geografia Médica e da Saúde, 251-262. Recuperado de: https://doi.org/10.14393/ Hygeia0054619

» Manzo, L. K. C. y Minello, A. (2020). Mothers, childcare duties, and remote working under COVID-19 lockdown in Italy: Cultivating communities of care. Dialogues in Human Geography, 10(2), 120-123. Recuperado de: https://doi. org/10.1177/2043820620934268

» Massey, D. (2012). Pelo espaço. Uma nova política da espacialidade. Rio de Janeiro: Bertrand.

» Matsumoto, P. S. S., Tenório Crepaldi, M., Avanzi Júnior, P. S., Buttler de Oliveira, M., De Sousa Regala, R. M., Vasco Rosseal, T. y Pereira Caetano de Lima, J. P. (2020). Mapeamento de Covid-19 e isolamento social: ferramentas de monitoramento e vigilância em saúde pública. Hygeia - Revista Brasileira de Geografia Médica e da Saúde, 298-311.

» Membe, A. (2011). Necropolítica. Tenerife: Melusina.

» Mello-Théry, N. Ap. de y Théry, H. (2020). A geopolítica do COVID-19. Espaço e Economia, 17. Recuperado de: https://doi.org/10.4000/espacoeconomia.11224

» Menchero Sánchez, M. (2020). Flujos turísticos, geopolítica y COVID-19: Cuando los turistas internacionales son vectores de transmisión. Geopolítica(s). Revista de estudios sobre espacio y poder, 11(Especial), 105-114. Recuperado de: https:// doi.org/10.5209/geop.69249

» Méndez, R. (2020). Sitiados por el Coronavirus: Consideraciones de un geógrafo. Reflexiones sobre la crisis COVID-19. Asociación Española de Geografía. Recuperado de https://www.age-geografia.es/site/wp-content/uploads/2020/03/ mendez-v1.pdf

» Millán, N. y Santander, G. (2020). El virus cosmopolita: Lecciones de la COVID-19 para la reconfiguración del Estado-Nación y la gobernanza global. Geopolítica(s). Revista de estudios sobre espacio y poder, 11(Especial), 251-263. Recuperado de: https://doi.org/10.5209/geop.69383

» Monié, F. (2020). A África subsaariana diante da pandemia de Coronavírus/ COVID-19: Difusão espacial, impactos e desafios. Espaço e Economia, 18. Recuperado de: https://doi.org/10.4000/espacoeconomia.13629

» Montemerli, R. (2020). Os desafios da Itália na emergência do coronavírus. Espaço e Economia, 17. Recuperado de: https://doi.org/10.4000/ espacoeconomia. 11312

" Mostafanezhad, M. (2020). Covid-19 is an unnatural disaster: Hope in revelatory moments of crisis. Tourism Geographies, 22(3), 639-645. Recuperado de: https:// doi.org/10.1080/14616688.2020.1763446

» Murray, I. y Cañada, E. (2020). La singularidad cultural como causa de la 
expansión del COVID-19 en España: Una respuesta. Reflexiones sobre la crisis COVID-19. Asociación Española de Geografía. Recuperado de https://www.agegeografia.es/site/wp-content/uploads/2020/04/murray-ernest-v1.pdf

» Nascimento Júnior, L., Augusto Werneck Ribeiro, E., Augusto Menegon, F., Salaib Springer, K., Monguilhot, M., Fernando Meliani, P. y da Silva Celestino Reginato, V. (2020). Suscetibilidade à Covid-19 em Santa Catarina: uma proposta metodológica. Hygeia - Revista Brasileira de Geografia Médica e da Saúde, 274286. Recuperado de: https://doi.org/10.14393/Hygeia0054564

» Nel-lo, O. (2020). La ciudad y la plaga. Reflexiones sobre la crisis COVID-19. Asociación Española de Geografía. Recuperado de: https://www.age-geografia. es/site/wp-content/uploads/2020/04/oriol-v1.pdf

»Nepal, S. K. (2020). Adventure travel and tourism after COVID-19 - business as usual or opportunity to reset? Tourism Geographies, 22(3), 646-650. Recuperado de: https://doi.org/10.1080/14616688.2020.1760926

» Neto, J. A. de S., y Castro, F. M. (2020). Capitalism über alles: Uma interpretação da pandemia de coronavírus no Brasil à luz da geografia radical de Neil Smith. Espaço e Economia, 18. Recuperado de: https://doi.org/10.4000/ espacoeconomia. 12104

» Neto, M. C. P. (2020). Sinais geográficos da Covid-19 no Brasil: correlações com a espacialização da sindrome respiratória aguda grave a partir do estado do Rio Grande do Norte. Revista Geolnterações, Assú, 1(4), 29-41. Recuperado de: http:// natal.uern.br/periodicos/index.php/RGI/article/view/2106

» Nossa, P. N. M. S. (2020). Preparação e cooperação internacional em cenários de emergência sanitária: fragilidades anunciadas num contexto de economia global. Hygeia - Revista Brasileira de Geografia Médica e da Saúde, 321-335. Recuperado de: https://doi.org/10.14393/Hygeia0054631

» Oliveira, A. L. de. (2020). A espacialidade aberta e relacional do lar: a arte de conciliar maternidade, trabalho doméstico e remoto na pandemia da covid-19. Revista Tamoios, 16(1), 154-166. Recuperado de: https://doi.org/10.12957/ tamoios.2020.50448

" Oppong, J. (2020) The African Covid-19 anomaly. African Geographical Review, 39, 282-288. Recuperado de: https://doi.org/10.1080/19376812.2020.1794918

" Oslender, U. (2020). Greta's Wrath; or «quédate en casa», Agamben: COVID-19 and the (Non-)State of Exception. Geopolítica(s). Revista de Estudios Sobre Espacio y Poder, 11(Especial), 275-283. Recuperado de: https://doi.org/10.5209/geop.69360

»Pastor, J. (2020). El (im)posible retorno del Estado al primer plano ante una catástrofe global. Geopolítica(s). Revista De Estudios Sobre Espacio Y Poder, 11(Especial), 165-172. Recuperado de: https://doi.org/10.5209/geop.69300

"Pereira Caldas dos Santos, J., Levy Ferreira Praça, H., Vouga Pereira, L., Gomes Albuquerque, H., y San Pedro Siqueira, A. (2020). A difusão espacial da Covid-19 no estado do Rio de Janeiro. Hygeia - Revista Brasileira de Geografia Médica e da Saúde, 263-273. Recuperado de: https://doi.org/10.14393/Hygeia0054624

»Pernecky, T. (2020). Critical tourism scholars: Brokers of hope. Tourism Geographies, 22(3), 657-666. Recuperado de: https://doi.or $\mathrm{g} / 10.1080 / 14616688.2020 .1760925$

»Pfrimer, M. H. y Barbosa, R. (2020). Brazil's war on COVID-19: Crisis, not conflict- 
Doctors, not generals. Dialogues in Human Geography, 10(2), 137-140. Recuperado de: https://doi.org/10.1177/2043820620924880

»Pillet Capdepón, F. (2020). La cuarentena: Una visión personal. Reflexiones sobre la crisis COVID-19. Asociación Española de Geografía. Recuperado de https:// www.age-geografia.es/site/wp-content/uploads/2020/04/pillet-v1.pdf

»Porto-Gonçalves, C. W. (2020a). De neoliberais e de keynesianos em tempos de Coronavírus. Espaço e Economia, 18. Recuperado de: https://doi.org/10.4000/ espacoeconomia.11699

"Porto-Gonçalves, C. W. (2020b). Escassez, economia e meio ambiente: 0 desserviço de Paulo Guedes. Espaço e Economia, 18. Recuperado de: https://doi. org/10.4000/espacoeconomia.11669

»Prideaux, B., Thompson, M. y Pabel, A. (2020). Lessons from COVID-19 can prepare global tourism for the economic transformation needed to combat climate change. Tourism Geographies, 22(3), 667-678. Recuperado de: https://doi. org/10.1080/14616688.2020.1762117

» Ramalho Barros, J., Barbara Gioia, T. y Silva Vasques, H. (2020). Proposta de índice para avaliação de situação de vulnerabilidade social ao Covid-19. Hygeia - Revista Brasileira de Geografia Médica e da Saúde, 361-369. Recuperado de: https://doi.org/10.14393/Hygeia0054537

» Ramos, T. T. (2020). Pandemia é pandemia em qualquer lugar - vivendo a crise da Covid-19 de fora dos grandes centros. Espaço e Economia, 18. Recuperado de: https://doi.org/10.4000/espacoeconomia. 11406

» Renaud, L. (2020). Reconsidering global mobility - distancing from mass cruise tourism in the aftermath of COVID-19. Tourism Geographies, 22(3), 679-689. Recuperado de: https://doi.org/10.1080/14616688.2020.1762116

»Ribeiro, E. A. W. (2020). Padrões espaços-temporais da rota do Covid19 (coronavirus) no estado de Santa Catarina, Brasil. Hygeia - Revista Brasileira de Geografia Médica e da Saúde, 16-24. Recuperado de: https://doi.org/10.14393/ Hygeia0054251

»Rocha, A. S. da. (2020). Globalização, gestão e acesso aos sistemas público e privado de saúde: A Baixada Fluminense no contexto da pandemia. Espaço e Economia, 18. Recuperado de: https://doi.org/10.4000/espacoeconomia.12672

》 Rodrigues, G. B. (2020). A distopia brasileira: O governo dos homens baixos. Espaço e Economia, 18. Recuperado de: https://doi.org/10.4000/ espacoeconomia.12871

» Rodrigues, J. N. y Azevedo, D. A. de. (2020). Pandemia do Coronavírus e (des) coordenação federativa: Evidências de um conflito político-territorial. Espaço e Economia, 18. Recuperado de: https://doi.org/10.4000/espacoeconomia.12282

» Romagosa, F. (2020). The COVID-19 crisis: Opportunities for sustainable and proximity tourism. Tourism Geographies, 22(3), 690-694. Recuperado de: https:// doi.org/10.1080/14616688.2020.1763447

» Romero, C. J., Tisnés, A. y Linares, S. (2020). Modelo de simulación del COVID-19 basado en agentes. Aplicación al caso argentino. Posición, 3, 1-22. Recuperado de https://716132a6-9cf5-45de-baee-6a15e46210f7.filesusr.com/ugd/df634b_76ede 6d8dd1841f2b3ff388ef4248e68.pdf

» Rossi, R. de C. y Silva, S. A. da. (2020). O Consórcio do Nordeste e o federalismo 
brasileiro em tempos de Covid-19. Espaço e Economia, 18. Recuperado de: https:// doi.org/10.4000/espacoeconomia.13776

» Roxo, R. (2020). Biopolítica, guerra híbrida e reestruturação do capitalismo: A globalização como ela é. Espaço e Economia, 18. Recuperado de: https://doi. org/10.4000/espacoeconomia.13376

» Rowen, I. (2020). The transformational festival as a subversive toolbox for a transformed tourism: Lessons from Burning Man for a COVID-19 world. Tourism Geographies, 22(3), 695-702. Recuperado de: https://doi.or $\mathrm{g} / 10.1080 / 14616688.2020 .1759132$

» Said, A. M. y Silva, J.C. da. (2020). A espacialidade da covid-19 e o pandemônio em meio a pandemia nas comunidades tradicionais da cajaíba - paraty. Revista Tamoios, 16(1), 206-231. Recuperado de: https://doi.org/10.12957/ tamoios.2020.50678

"Salinas, S. V. y Nochebuena, G. (2020). Análisis espacial de vulnerabilidad y riesgo en salud por COVID-19 en el estado de Guerrero, México. Posición, 3, 1-14. Recuperado de: https://716132a6-9cf5-45de-baee-6a15e46210f7.filesusr.com/ ugd/df634b_c6e5040acd1a4f93865d73aad0e63774.pdf

"Sánchez, J.L. (2020). Éticas, Geografía y post-pandemia: Una cuarentena con Max Weber. Reflexiones sobre la crisis COVID-19. Asociación Española de Geografía. Recuperado de: https://www.age-geografia.es/site/wp-content/uploads/2020/05/ jos\%C3\%A9-luis-s\%C3\%A1nchez-v1.pdf

» Santana Juárez, M. V., Castañeda, G. S., Carillo, C. S., Carrillo, R. S. y Alcántara, R. O. (2020). Covid-19 en México: asociación espacial de cara a la fase tres. Hygeia - Revista Brasileira de Geografia Médica e da Saúde, 36-48. Recuperado de: https:// doi.org/10.14393/Hygeia0054317

»Santos, M. (2004). Por otra globalización. Del pensamiento único a la conciencia universal. Bogotá: Convenio Andrés Bello.

"Santos Júnior, C. J. dos, Costa, P. J. M. de S., Silva, J. V. dos S., Souza, A. K. P., Silva, J. P. y Rocha, T. J. M. (2020). Tecnologias digitais e de geoprocessamento aplicadas ao monitoramento da doença de coronovírus 2019 (Covid-19). Hygeia - Revista Brasileira de Geografia Médica e da Saúde, 1-10. Recuperado de: https:// doi.org/10.14393/Hygeia0053912

»Saracho López, F. J. (2020). Espacialidad y pandemia: la crisis del coronavirus vista desde la geopolítica negativa. Geopolítica(s). Revista De Estudios Sobre Espacio Y Poder, 11(Especial), 69-79. Recuperado de: https://doi.org/10.5209/ geop.69149

»Sierra, J. R. (2020a). La inexistente respuesta regional a la COVID-19 en América Latina. Geopolítica(s). Revista de estudios sobre espacio y poder, 11(Especial), 209-222. Recuperado de: https://doi.org/10.5209/geop.69324

»Sierra, J. R. (2020b). Una aproximación (geo) política a la crisis de la Covid-19 en América Latina. Journal of Latin American Geography, 19(3), 194-201. Recuperado de: https://muse.jhu.edu/article/760939

» Silva, C. A. da, Sampaio, K. D. S., Buch, C. L., Euzêbio, R. C. y Pinto, P. B. A. (2020). Política pública da previdência social e trabalhadores da pesca artesanal: dilemas estruturais em contextos conjunturais do covid-19. Revista Tamoios, 16(1), 88107. Recuperado de: https://doi.org/10.12957/tamoios.2020.50764 
》Silva, J. B. da y Muniz, A. M. V. (2020). Pandemia do Coronavírus no Brasil: Impactos no Território Cearense. Espaço e Economia, 17. Recuperado de: https:// doi.org/10.4000/espacoeconomia.10501

"Silva, O. T. da. (2020). 0 salto ainda mais mortal que o da mercadoria e a pandemia do coronavírus. Espaço e Economia, 17. Recuperado de: https://doi. org/10.4000/espacoeconomia.10822

» Simão, M. P. (2020). Como as favelas nos ajudam a pensar a cidade após a pandemia do coronavírus? Revista Tamoios, 16(1), 50-62. Recuperado de: https:// doi.org/10.12957/tamoios.2020.50437

"Soares da Silva, M. H., Dubos Raoul, M. y Ribeiro Oquendo Cabrero, D. (2020). Análise sobre risco e vulnerabilidade à Covid-19 no estado de Mato Grosso do Sul. Hygeia - Revista Brasileira de Geografia Médica e da Saúde, 164-174. Recuperado de: https://doi.org/10.14393/Hygeia0054402

» Soares, A. F. S., Nunes, B. C. R., Costa, F. C. R., Silva, L. F. de M. y Souza, L. P. S. e. (2020). Modelagem ambiental para Covid-19 (Sars-Cov-2) em sistemas de esgotamento sanitário como instrumento auxiliar nas ações de saúde pública. Hygeia - Revista Brasileira de Geografia Médica e da Saúde, 19(3), 194-201. Recuperado de: https://doi.org/10.14393/Hygeia0054636

"Sodoré, A. A., Monié, F. y Pouya, L. P. (2020). Distribuição geográfica e difusão espacial do coronavírus/covid-19 no burquina fasso (áfrica ocidental). Revista Tamoios, 16(1), 167-187. Recuperado de: https://doi.org/10.12957/ tamoios.2020.50604

»Sotela, O. B. y Mayorga M.A.S. (2020). Comportamiento espacial de la pandemia COVID-19 en Costa Rica durante los meses de marzo y abril de 2020 mediante un análisis de autocorrelación espacial. Posición, 3, 1-17. Recuperado de: https://716132a6-9cf5-45de-baee-6a15e46210f7.filesusr.com/ugd/df634b_ d5ed424dc80043de8412f1aea1ddda23.pdf

»Souza, M. V. M. de y Ferreira Júnior, D. B. (2020). Rede urbana, interações espaciais e a geografia da saúde: Análise da trajetória da Covid-19 no estado do Pará. Espaço e Economia, 18. Recuperado de: https://doi.org/10.4000/ espacoeconomia.13146

»Sparke, M y Anguelov, D. (2020). Contextualizing coronavirus geographically. Transactions. Institute of British Geographers, 45, 498-508. Recuperado de: https:// rgs-ibg.onlinelibrary.wiley.com/doi/full/10.1111/tran.12389

"Springer, S. (2020). Caring geographies: The COVID-19 interregnum and a return to mutual aid. Dialogues in Human Geography, 10(2), 112-115. Recuperado de: https://doi.org/10.1177/2043820620931277

》Stankov, U., Filimonau, V. y Vujičić, M. D. (2020). A mindful shift: An opportunity for mindfulness-driven tourism in a post-pandemic world. Tourism Geographies, 22(3), 703-712. Recuperado de: https://doi.org/10.1080/14616688.2020.1768432

» Tapia, M. y Bouza., J. (2020). Lo que la pandemia deja al descubierto. El COVID-19 en España. Espaço e Economia, 17. Recuperado de: https://doi.org/10.4000/ espacoeconomia.10946

"Tomassini, L. y Cavagnaro, E. (2020). The novel spaces and power-geometries in tourism and hospitality after 2020 will belong to the "local". Tourism Geographies, 22(3), 713-719. Recuperado de: https://doi.org/10.1080/14616688.2020.1757747 
» Tremblay-Huet, S. (2020). COVID-19 leads to a new context for the "right to tourism": A reset of tourists' perspectives on space appropriation is needed. Tourism Geographies, 22(3), 720-723. Recuperado de https://doi.or $\mathrm{g} / 10.1080 / 14616688.2020 .1759136$

»Vallejo, M. E. (2020). Geografía política de los cuidados (O por qué la pandemia del coronavirus confinó a buena parte del Norte global). Geopolítica(s). Revista de estudios sobre espacio y poder, 11(Especial), 127-140. Recuperado de: https://doi. org/10.5209/geop.69252

》Vecchio, G. y Tiznado-Aitken, I. (2020) (Im)Mobility and Health in Santiago de Chile. Journal of Latin American Geography, 19(3), 240-247. Recuperado de: https://muse.jhu.edu/article/760905

»Vegas Gallo, E. (2020). Factores socioambientales del Covid-19. Reflexiones sobre la crisis COVID-19. Asociación Española de Geografía. Recuperado de: https:// www.age-geografia.es/site/wp-content/uploads/2020/04/edwin-vegas-v1.pdf

»Vicente Ferreira, R., Carvalho, D. M., Souza, A. L. de P., Martines, M. R. y Assunção, L. M. de. (2020). Covid-19 na região de saúde Triângulo Sul, MG: uma perspectiva cartográfica. Hygeia - Revista Brasileira de Geografia Médica e da Saúde, 49-59. Recuperado de: https://doi.org/10.14393/Hygeia0054379

"Wagner, A., Soares, A. S., Ribeiro, E. A. W., Friestino, J. K. O., Lovatto, M. V. P., Faria, R. M. y Weissheimer, W. A. (2020). Vulnerabilidades para gestantes e puérperas durante a pandemia da Covid-19 no estado de Santa Catarina, brasil. Hygeia - Revista Brasileira de Geografia Médica e da Saúde, 398-406. Recuperado de: https://doi.org/10.14393/Hygeia0054630

»Zanotelli, C. L., y Dota, E. M. (2020). A questão da desigualdade territorial municipal no Espírito Santo face à pandemia do coronavirus e a importância da existência de um Estado de bem estar social em defesa da sociedade. Espaço e Economia, 17. Recuperado de: https://doi.org/10.4000/espacoeconomia.10207

»Zapata, V. (2020). El tiempo de lo comunitario. Reflexiones sobre la crisis COVID-19. Asociación Española de Geografía. Recuperado de: https://www.agegeografia.es/site/wp-content/uploads/2020/04/vicente-zapata-v1.pdf

\section{Perla Zusman / perlazusman@yahoo.es}

Doctora en Geografía Humana (Universidad Autónoma de Barcelona). Magíster en Integración de América Latina (Universidad de São Paulo). Investigadora Independiente del CONICET con sede en el Instituto de Geografía de la Universidad de Buenos Aires. Docente titular regular de la Facultad de Filosofía y Letras, UBA en la Asignatura Introducción a la Geografía. Sus líneas de investigación son: Historia de las tradiciones geográficas en Argentina y Brasil; Formación territorial en Argentina (del período colonial al de formación de Estado); Representaciones culturales del territorio y de las fronteras; Paisaje y patrimonio en tiempo de globalización en Argentina. Es integrante del Grupo de estudios sobre Cultura, Naturaleza y Territorio con sede en el Instituto de Geografía de la UBA.

\section{Gabriela Landini / gaby_landini@hotmail.com}

Licenciada en Historia (Universidad de Buenos Aires), técnica en Gestión del Arte y la Cultura (Universidad Nacional de Tres de Febrero). Está cursando la Especialización en Museos, Transmisión Cultural y Manejo de Colecciones antropológicas e históricas 
Perla Zusman, GonZalo Lus BIETtI, Gabriela LandinI

(UBA). Su tesis de licenciatura analizó el proceso de configuración socioespacial de San Martín de los Andes en el marco de la creación de Parques Nacionales. Actualmente sus investigaciones se centran en las dinámicas territoriales asociadas al desarrollo de la actividad turística en la Norpatagonia argentina.

\section{Gonzalo Lus Bietti / g.lus@hotmail.com}

Licenciado en Geografía (Universidad de Buenos Aires). Doctorando en la Universidad de Buenos Aires (mención Geografía). Becario de investigación UBACYT (Instituto de Geografía "Romualdo Ardissone"). Integrante del grupo de estudios de Cultura, Naturaleza y Territorio. Trabaja en temas afines al pensamiento geográfico, a la historia social de la geografía y la epistemología de la geografía. 